\title{
Determinants of Prolonged Length of Stay among Patients with Road Traffic Injury at the Philippine General Hospital: A Retrospective Cohort Study
}

\author{
Jinky Leilanie Lu, MOH, PhD, ${ }^{1}$ Teodoro J. Herbosa, MD² and Sophia Francesca D. Lu, MOS${ }^{3}$ \\ ${ }^{1}$ National Institutes of Health, University of the Philippines Manila \\ ${ }^{2}$ Department of Emergency Medicine and Department of Surgery, College of Medicine and Philippine General Hospital, University of the Philippines Manila \\ ${ }^{3}$ School of Labor and Industrial Relations, University of the Philippines Diliman
}

\begin{abstract}
Introduction. Road traffic injuries are among the leading causes of preventable death, claiming around 7000 lives every year. Furthermore, road traffic can injure or disable thousands more every year in the Philippines.
\end{abstract}

Objectives. This study determined the hospital length-of-stay patterns and risk factors for a prolonged length of stay in a tertiary hospital after road traffic injury.

Methods. A retrospective cohort study was conducted to determine the determinants of the length of stay in the Philippine General Hospital (PGH) among road traffic injury victims for the year 2016. Length of stay was recorded according to the median. The other variables were cross-tabulated against the length of stay, and each of their crude odds ratios along with corresponding $\mathrm{p}$-values were presented. Continuous variables were analyzed using Wilcoxon Mann-Whitney U-test. The predictor model for the determinants of prolonged length of stay in the hospital was built using forward selection. Likelihood-ratio test was used to compare the model with and without the exposure variable.

Results. A total of 427 road traffic injury victims were admitted to the Philippine General Hospital in 2016. The mean age of the patients was 31.55 years $( \pm 14.97)$ with a median age of 29 years. The majority of patients were males $(82.4 \%)$ and single (60.8\%). Most patients were riding a motorcycle during the time of the accident $(64.2 \%)$ while $20 \%$ were pedestrians. The majority of the victims were intoxicated $(74.3 \%)$ and were not using helmets $(57.1 \%)$ at the time of the accident. Most of the victims received first aid (69.2\%) and the mean time of admission was $3.03( \pm 13.31)$ days while the median time to admission was 12 hours. Receiving first aid $(p<0.01)$, availed services $(p<0.01)$, and married civil status $(p=0.04)$ were found to be strongly associated with length of hospital stay. Without controlling for any confounders, pay patients ( $\mathrm{OR}=3.46,95 \% \mathrm{Cl}: 1.3,-9.87)$, elective patients $(\mathrm{OR}=7.88,95 \% \mathrm{Cl}: 2.64,31.61)$, and those in non-trauma wards $(\mathrm{OR}=2.07,95 \% \mathrm{Cl}: 1.29,3.36)$ had higher odds for longer hospitalization stay. On the other hand, those who did not receive first aid $(\mathrm{OR}=0.55, \mathrm{Cl}: 0.35,0.85)$ had lower odds for prolonged hospitalization. Those who suffered face injury and did not suffer external injuries had a higher mean rank, suggesting a longer length of hospital stay. On the other hand, upon controlling variables found to be associated with previous studies, those with low Glasgow coma scale (GCS) scores were 2.77 times $(95 \% \mathrm{Cl}: 1.13,6.91)$ more likely to stay longer in the hospital.

Conclusion. The type of victim, mortality status, age, and sex were found to be important determinants of prolonged hospitalization. To lessen the number of fatalities and road trauma injuries, laws on road safety should be strictly and properly implemented. Shared responsibility of all road users is also important in improving the safe usage of roads.

Key Words: Glasgow coma score, length of stay, traffic accident, traffic crash, trauma

Corresponding author: Teodoro J. Herbosa, MD

Department of Emergency Medicine and Department of Surgery

Philippine General Hospital, University of the Philippines Manila

Taft Avenue, Ermita, Manila 1000, Philippines

Email: tjherbosa@up.edu.ph 


\section{INTRODUCTION}

Road traffic injuries are among the leading causes of preventable death, claiming around 7000 lives every year. Furthermore, road traffic disables thousands more every year in the Philippines. Injuries to the head and neck due to road traffic accidents are the main causes of death and disability. ${ }^{1}$ In addition, road traffic crashes contribute a significant amount to the demand for resources, especially health resources. From one study in the United States, road traffic injuries are thought to cost USD 230.6 billion, with USD 32.6 billion in medical charges alone. ${ }^{2}$ From another study in Iran, road traffic injuries approximately cost USD 2 billion, which was a significant amount considering that it is a middle-income country. ${ }^{3}$

In a study on the social and economic burden of road traffic injuries in the Philippines, the estimated cost of death and injuries in 2014 due to accidents in the road was Php 1.213 billion (USD 60.5 billion) on medical costs alone, not including the costs for lost productivity due to illnesses and injuries that amounts to PhP 26.519 billion (USD 1.32 billion). ${ }^{4}$

Published studies on the length of hospitalization and the economic and/or healthcare costs of road traffic injuries in the Philippines are lacking. Prolonged length of stay in hospitals consumes material and manpower resources. Previous studies showed that age, sex, the vehicle of the patient, severity of the injury, and mortality were determinants of prolonged hospital stay. ${ }^{2,3}$ This study is the first that will describe hospital length-of-stay patterns in the country, as well as determine risk factors for a prolonged length of stay in the hospital after road traffic injury.

\section{MATERIALS AND METHODS}

A retrospective cohort study was conducted to determine the determinants of the length of stay in the Philippine General Hospital (PGH) among road traffic injury victims for the year 2016.

The researchers utilized data from the PGH Integrated Surgical Information System (PGH-ISIS), an electronic online database that houses clinical abstracts of patients admitted in the PGH trauma department. The researchers requested limited access to the PGH-ISIS portal after securing an approval from the University of the Philippines Manila Research Ethics Board (UPM-REB).

Socio-demographic information (e.g., age, sex, civil status), pertinent information regarding the accident (e.g., time of injury, type of victim, time to admission, whether or not the victim received first aid, the vehicle of the patient and other parties to the accident, intoxication, and helmet use), as well as pertinent admission-related information (e.g., charity/ pay status, emergency/elective status, inpatient/outpatient, the ward where the patient is admitted, body part injured, and length of stay) were abstracted from the patient charts and cleaned accordingly. The Glasgow Coma Scale (GCS) scores of patients were also gathered as a measure for the intensity of head trauma. The American College of Surgeons defined a GCS score of 13-15 as mild head injury; 9-12 as moderate head injury, and 8 and below as severe head injury. For this study, GCS scores were classified as high (13-15) or low (12 and below) for the descriptive analysis, but numerical GCS scores were considered for the inferential statistics.

The variables considered for the determinants of length of hospitalization were derived from a modified variant of the conceptual framework from Wright et al., which studied the factors influencing the length of hospital stay for patients with heart failure. ${ }^{1}$ In the database, not all these determinants were available (Appendix 1).

Length of stay was recorded using its median as the classifier. Length of Stay lower than the median were classified as "Short Length of Stay", while length of stay higher than the median were classified as "Long Length of Stay". The other variables were cross-tabulated against the length of stay, and each of their crude odds ratios as well as their corresponding $\mathrm{p}$-value was obtained. Continuous variables were analyzed using Wilcoxon Mann-Whitney U-test to compare the distributions of these variables according to the recorded length of stay. Variables that are thought to be unimportant determinants and/or those who have at least $60 \%$ of data missing are not considered in the multivariate analysis. Observations with at least one missing among the variables considered in the multivariate analysis are dropped.

Length of hospital stay was also tested against body part injury. The distribution of length of hospital stay was a highly right-skewed distribution, which violated the assumption of most parametric tests. A study by Chazard et al. in 2017 suggested Kruskal-Wallis test as a method of analyzing the length of hospital stay with an acceptable Type I error and high power. ${ }^{5}$

The predictor model for the determinants of prolonged length of stay in the hospital was built using forward selection. A model without any exposure variables was fitted first, and a model with the lowest $\mathrm{p}$-value was fitted subsequently. The likelihood ratio test (LRT) was used to compare models with and without the exposure variable. The LRT was used to compare the goodness of fit of the model when independent variables are introduced. Statistical significance for the independent variable was achieved when the model with the exposure variable achieved a statistically better fit than the model without the variable. If the likelihood-ratio test was statistically significant, the variable was retained in the model, otherwise, it was not included. This iterative process continued with the second-lowest $\mathrm{p}$-value until the variable with the highest $\mathrm{p}$-values were fitted. Variables that are a priori associated with prolonged length of stay (age, sex, vehicle of patient, severity of injury, and mortality) were retained in the model regardless of whether the likelihood ratio test for these variables was not statistically significant. The final model was expected to contain variables that were 
found to be statistically significant in the likelihood ratio test as well as the variables that were forced into the model. Among any variables that were found to be auto-correlated, only one variable was considered.

The National Institutes of Health, University of the Philippines issued Ethics Clearance for this research study. This is also funded by the Emerging Interdisciplinary Research (EIDR) of the University of the Philippines System.

The study is limited by the data that is available in PGH's Integrated Surgical Information System (ISIS) online database. PGH-ISIS houses digital clinical abstracts of patients that were admitted to PGH. The system only includes patients that were admitted to the hospital, hence ER consults and ER deaths, pre-hospital deaths, and death on arrivals are excluded.

\section{RESULTS}

There were 427 road traffic injury victims who were admitted during the period in this study. Most patients were

Table 1. Distribution of patients according to demographic variables and crash details

\begin{tabular}{|c|c|c|}
\hline Demographic Variables and Crash Details & Frequency & $\begin{array}{l}\text { Valid } \\
\text { Percent }\end{array}$ \\
\hline \multicolumn{3}{|l|}{ Sex } \\
\hline Male & 352 & 82.4 \\
\hline Female & 75 & 18.6 \\
\hline \multicolumn{3}{|l|}{ Civil status } \\
\hline Single & 255 & 60.8 \\
\hline Married/Common-law & 152 & 36.3 \\
\hline Widow/Widower & 12 & 2.9 \\
\hline Missing & 8 & \\
\hline \multicolumn{3}{|l|}{ Road User Classification } \\
\hline Driver & 276 & 68.0 \\
\hline Passenger & 48 & 11.8 \\
\hline Pedestrian & 82 & 20.2 \\
\hline Missing & 21 & \\
\hline \multicolumn{3}{|l|}{ Type of vehicle at the time of the accident } \\
\hline Bicycle & 22 & 5.4 \\
\hline Car/Jeep/Van/Truck & 20 & 4.9 \\
\hline Tricycle/Kuliglig & 23 & 5.6 \\
\hline Motorcycle & 263 & 64.2 \\
\hline No vehicle (pedestrian) & 82 & 20.0 \\
\hline Missing & 17 & \\
\hline \multicolumn{3}{|l|}{ Other party or element involved in the accident } \\
\hline Road/ground/pavement/gutter & 92 & 23.1 \\
\hline Other obstacles & 32 & 8.0 \\
\hline Bicycle/Tricycle & 30 & 7.5 \\
\hline Motorcycle & 65 & 16.3 \\
\hline Car/Van/Pickup/L300/Owner Type Jeepney & 97 & 24.4 \\
\hline Public Utility Jeep/Bus & 37 & 9.3 \\
\hline Truck/Forklift/Train & 38 & 9.6 \\
\hline Pedestrian/Animals & 7 & 1.8 \\
\hline Missing & 29 & \\
\hline
\end{tabular}

seen during October (24.6\%), followed by May (13.9\%) and June (10.7\%). The months of November (2\%) and December (2\%) had the lowest admissions (Appendix 2).

Age ranged from a minimum of 0 (infant aged less than 1 year) to a maximum of 78 . The distribution of age was bimodal, initially peaking for 4- to 8-year-olds, then finally peaking for 25- to 28-year-olds. The majority of patients were between 20 to 60 years old (Figure 2). The mean age was $31.55( \pm 14.97)$ years while the median age was 29 years. All quantitative variables (age, time to admission, length of stay) were right-skewed. The majority (82.4\%) were men and only $18.6 \%$ were women. Most of them were single (60.8\%), but many were also married or living under common law $(36.3 \%)$, while the minority were widows or widowers (2.9\%) (Appendix 3).

The majority of the patients were drivers (68\%), while the rest were pedestrians (20.2\%) and passengers (11.8\%). Most patients were riding a motorcycle during the time of the accident (64.2\%), while the rest, tricycle or "kuliglig" (5.6\%), bicycle (5.4\%), and a car, jeep, van, or truck (4.9\%). There were also some who were pedestrians during the time of the accident (20\%). The other parties involved in the accident were car, van, pickup, L300, or owner type jeepney (24\%); road, ground, pavement, or gutter (23.1\%); motorcycle (16.3\%); truck, forklift, or train (9.6\%); public utility jeep or bus (9.3\%); other obstacles (8\%); bicycle or tricycle $(7.5 \%)$, and pedestrian or animals (1.8\%) (Table 1$)$.

Only a small percentage of the patients had comorbidities or deformities (10.5\%) while the majority had none (89.5\%) (Table 3). Most of the patients were intoxicated during the time of the accident (74.3\%). Alcohol intoxication is generally determined by the attending physician through

Table 2. Distribution of patient condition prior to accident

\begin{tabular}{|c|c|c|}
\hline Variable & Frequency & Valid Percent \\
\hline \multicolumn{3}{|l|}{ Risk factors } \\
\hline No comorbidity/deformity & 382 & 89.5 \\
\hline Has comorbidity/deformity & 45 & 10.5 \\
\hline Missing & 0 & \\
\hline \multicolumn{3}{|c|}{ Intoxicated or not at the time of the accident } \\
\hline Not intoxicated & 46 & 25.7 \\
\hline Intoxicated & 133 & 74.3 \\
\hline Missing & 248 & \\
\hline \multicolumn{3}{|c|}{ Wearing a helmet at the time of the accident } \\
\hline Used helmet & 54 & 42.9 \\
\hline Did not use helmet & 72 & 57.1 \\
\hline Missing & 301 & \\
\hline \multicolumn{3}{|c|}{ First aid received at the time of the accident } \\
\hline Received first aid & 287 & 69.2 \\
\hline Did not receive first aid & 128 & 30.8 \\
\hline Missing & 12 & \\
\hline \multicolumn{3}{|l|}{ Time of injury } \\
\hline Morning (6:00 AM - 5:59 PM) & 148 & 36.2 \\
\hline Evening (6:00 PM - 5:59 AM) & 261 & 63.8 \\
\hline Missing & 18 & \\
\hline
\end{tabular}


Table 3. Distribution of patients according to body injuries affecting length of hospital stay

\begin{tabular}{|c|c|c|c|c|c|c|}
\hline \multicolumn{2}{|c|}{ Body Part Injured } & \multicolumn{2}{|r|}{ Frequency } & \multicolumn{3}{|c|}{ Valid Percent } \\
\hline \multicolumn{3}{|l|}{ Head and neck } & \multicolumn{2}{|l|}{240} & \multicolumn{2}{|l|}{57.00} \\
\hline \multicolumn{3}{|l|}{ Face } & \multicolumn{2}{|l|}{234} & \multicolumn{2}{|l|}{55.58} \\
\hline \multicolumn{3}{|l|}{ Chest } & \multicolumn{2}{|l|}{172} & \multicolumn{2}{|l|}{40.86} \\
\hline \multicolumn{3}{|l|}{ Abdomen } & \multicolumn{2}{|l|}{191} & \multicolumn{2}{|l|}{45.37} \\
\hline \multicolumn{3}{|l|}{ Extremity } & \multicolumn{2}{|l|}{328} & \multicolumn{2}{|l|}{77.91} \\
\hline \multicolumn{3}{|l|}{ External Injury } & \multicolumn{2}{|l|}{237} & \multicolumn{2}{|l|}{56.43} \\
\hline \multicolumn{7}{|c|}{ Significant Associations for Length of Hospital Stay } \\
\hline Variable & Sub-category & $\mathbf{N}$ & Mean Rank & Kruskal-Wallis & -Square & p-value \\
\hline \multirow[t]{2}{*}{ Head and neck injury } & No & 181 & 214.98 & \multirow{2}{*}{\multicolumn{2}{|c|}{0.44}} & 0.51 \\
\hline & Yes & 239 & 207.11 & & & \\
\hline \multirow[t]{2}{*}{ Face injury } & No & 186 & 193.56 & \multirow{2}{*}{\multicolumn{2}{|c|}{6.64}} & 0.01 \\
\hline & Yes & 234 & 223.96 & & & \\
\hline \multirow[t]{2}{*}{ Chest injury } & No & 248 & 203.53 & \multirow{2}{*}{\multicolumn{2}{|c|}{2.04}} & 0.15 \\
\hline & Yes & 172 & 220.55 & & & \\
\hline \multirow[t]{2}{*}{ Abdomen injury } & No & 229 & 205.76 & \multirow{2}{*}{\multicolumn{2}{|c|}{0.78}} & 0.38 \\
\hline & Yes & 191 & 216.18 & & & \\
\hline \multirow[t]{2}{*}{ Extremity injury } & No & 92 & 191.95 & \multirow{2}{*}{\multicolumn{2}{|c|}{2.81}} & 0.09 \\
\hline & Yes & 328 & 215.70 & & & \\
\hline \multirow[t]{2}{*}{ External Injury } & No & 183 & 228.85 & \multirow{2}{*}{\multicolumn{2}{|c|}{7.57}} & 0.01 \\
\hline & Yes & 237 & 196.33 & & & \\
\hline
\end{tabular}

Note: The total sample for the Kruskal-Wallis result is less than that of the frequency table. This is due to missing values when two variables are considered in the analysis.

subjective analysis of the smell of the breath of the patient. However, since this is based on abstracted clinical data, there was no information included as to whether alcohol was tested objectively through blood alcohol levels, or subjectively through the smell of the patient's breath. The majority were also not wearing helmets during the time of the accident (57.1\%) (Table 3). A big percentage of the patients reported that they received first aid during the time of the accident (69.2\%). While it is relevant to studying the length of stay, there is no data included in the database as to what type of first aid the patient received. As to the time of injury, most were seen to have taken place in the evening (63.8\%) and are specifically highest in between 7:00 PM to 11:00 PM (Table 2).

The time to admission ranged from a minimum of 20 minutes ( 0.01 days) to 180 days. Patients with larger values for time to admission were usually elective patients. The mean time to admission was $3.03( \pm 13.31)$ days while median time to admission was 12 hours (Appendix 4).

Body parts of patients that suffered injury were extremities (77.9\%), head and neck (57.0\%), external injuries (56.4\%), face (55.6\%), abdomen (45.4\%), and chest (40.9\%), (Table 3).

The length of hospital stay was tested against injury to various body parts. The distribution of length of hospital stay was a highly right-skewed distribution, which violates the assumption of most parametric tests. A study by Chazard et al. in 2017 suggested Kruskal-Wallis test as a method of analyzing this statistical issue with an acceptable Type
I error and high power. ${ }^{5}$ Injuries to the face and external injuries showed significant association with the length of hospital stay at a $95 \%$ significance level. Those who suffered face injuries showed a higher mean rank and a longer length of hospital stay. On the other hand, those who suffered external injuries had a lower mean rank and a lower length of hospital stay (Table 3).

The GCS scores of those with head injuries was used as the proxy variable to measure the severity of injury upon admission. Lower scores indicated lower levels of consciousness ${ }^{4}$ and was usually associated with traumatic brain injury. ${ }^{5}$ Majority had GCS scores that showed mild head injuries: $62.6 \%$ had GCS 15, 9.4\% had GCS 14, and 7.4\% had GCS 13 (Appendix 5).

Almost all patients were admitted as emergency cases (93.2\%) and charity patients (93.7\%). All patients except one who was considered an outpatient case $(0.2 \%)$ were admitted to the hospital (99.8\%) (Table 4).

The majority of the patients were treated under the trauma service (76.1\%), followed by the plastic surgery service (8.9\%) and the service of the surgeon-on-duty (6.3\%) (Appendix 6).

Almost all patients improved with the treatment received (91\%). Some had unchanged medical conditions (6\%), while some died (3\%), and others left against medical advice (0\%) (Appendix 7).

Time to discharge ranged from a minimum of 12 hours (assumed value for those who were discharged less than 24 hours) to a maximum of 81 days) (Appendix 8). 
Table 4. Distribution of patients according to admission details $(\mathrm{N}=427)$

\begin{tabular}{lcc}
\multicolumn{1}{c}{ Admission Details } & Frequency & Valid Percent \\
Emergency or elective & & \\
Emergency & 398 & 93.2 \\
Elective & 29 & 6.8 \\
\hline Pay or charity & & \\
Charity & 400 & 93.7 \\
Pay & 27 & 6.3 \\
\hline Inpatient or outpatient & & \\
Admitted & 426 & 99.8 \\
Outpatient & 1 & 0.2 \\
\hline
\end{tabular}

Most of the patients obtained their injuries at 9:00 PM (7.8\%), while many also had them at 11:00 PM (6.4\%) and 8:00 PM (6.1\%) (Appendix 9).

Age and time of injury did not differ significantly between those who have a short length of stay and those who have a long length of stay. However, the time to admission differed significantly between those who had a short length of stay and those who had a long length of stay $(\mathrm{p}<0.01)$. Those who stayed in PGH longer were found to have a higher median time to admission.

Receiving first aid, the service availed or ward where the patient was staying, whether the patient is an emergency or elective patient, and whether the patient is a charity or pay patient were all very strongly associated with length of stay in the hospital. Civil status was strongly associated with the length of stay in the hospital (Appendix 10).

Without controlling for any confounders, there was longer hospital stay for pay patients $(\mathrm{OR}=3.46,95 \% \mathrm{CI}$ : $1.36,9.87)$, elective patients $(\mathrm{OR}=7.88,95 \% \mathrm{CI}: 2.64$, $31.61)$, and those who were in non-trauma wards $(\mathrm{OR}=2.07$, 95\% CI: 1.29, 3.36),. Receiving first aid was also associated with prolonged hospitalization $(\mathrm{OR}=0.55,95 \% \mathrm{CI}$ : 0.35, $0.85)$. However, the database analyzed in this study did not contain the type of first aid as well as the time the first aid was given to the patient. The precision of assessing the effect of first aid on the length of hospitalization can be increased if better data can be collected. Without controlling for any confounders, those who were married were 1.52 (95\% CI: 1.00, 2.32) times more likely to stay longer in $\mathrm{PGH}$ as compared to those who were single or widow/widower (Appendix 10).

From the regression analysis and upon controlling for variables from previous studies that were found to be associated with the outcome, GCS, type of victim, mortality, age, and sex were found to be important determinants of prolonged hospital stay (Table 5). Intoxication during the time of the accident and helmet use were not considered in the regression analysis due to substantial missing data. Admission, which was not considered to be important in the analysis, was not included to prevent separation. Despite the substantial missing data, GCS score was kept in the analysis as it was known to be an important predictor.
Table 5. Determinants of the length of stay of road traffic injury victims

\begin{tabular}{lccc}
\multicolumn{1}{c}{ Variable } & Odds Ratio & $95 \% \mathrm{Cl}$ & p-value \\
\hline GCS & 2.77 & $1.13-6.91$ & $0.03^{*}$ \\
\hline $\begin{array}{l}\text { Type of Victim } \\
\text { Passenger }\end{array}$ & 0.22 & $0.06-0.84$ & $0.03^{*}$ \\
Pedestrian & 0.50 & $0.21-1.14$ & 0.10 \\
\hline Died & 0.14 & $0.02-0.79$ & $0.03^{*}$ \\
\hline Age & 0.99 & $0.97-1.01$ & 0.48 \\
\hline Sex & 1.07 & $0.37-3.08$ & 0.90 \\
\hline
\end{tabular}

*Significant

$\mathrm{Cl}$, Confidence interval

Those who had a low GCS score (i.e., more severe cases) were found to be 2.77 (95\% CI: 1.13, 6.91) times more likely to stay longer in the hospital as compared to those who had high GCS score. Those who were passengers were 78\% (95\% CI: $0.06,0.84)$ less likely to stay longer in the PGH as compared to the drivers. Those who died were $86 \%$ (OR, $0.22,95 \%$ CI: $0.02,0.79)$ less likely to stay longer in the PGH as compared to those who were alive. There is no association between age and length of hospital stay (OR 0.99, 95\% CI: $0.97,1.01$ ) while being a pedestrian was not significantly associated with hospital stay (OR $0.5,95 \%$ CI: $0.21,1.14$ ) (Table 5).

Only 176 patients had complete data for all study variables and were considered for the logistic regression analysis. The type of victim and the vehicle of the patient were found to be autocorrelated. The type of victim was retained in the model as the likelihood-ratio test for this variable was statistically significant. Although the vehicle of the patient was found to be associated with prolonged hospital stay in previous studies, the likelihood ratio test for this variable was not statistically significant and was dropped from the study.

\section{DISCUSSION}

The present study found that the determinants of prolonged stay in the $\mathrm{PGH}$ among road traffic injury patients are their GCS mortality status, age, sex, and type of victim or whether they were a driver, a passenger or a pedestrian.

The study was limited by the data that was available in PGH's Integrated Surgical Information System (ISIS) online database. PGH-ISIS houses digital clinical abstracts of patients that were admitted to PGH. The system only included patients that were admitted to the hospital, hence ER consults and ER deaths, pre-hospital deaths, and death on arrivals were excluded.

GCS score is a proxy variable to measure the severity of the injury upon admission. In a cross-sectional retrospective study conducted in the central rural region of the Kingdom of Saudi Arabia, it was seen that injuries to the head, neck, chest, abdomen, internal organs, spine or pelvis, yielded a 
statistically significant lower mean GCS score compared to those who did not suffer injuries to the said body parts. Lower scores indicate lower levels of consciousness ${ }^{6}$ and is usually associated with traumatic brain injury, depending on its severity. ${ }^{7}$ Although it is not possible to measure this accurately in some cases such as in intoxication, intubation, medication use or presence of other injuries influencing ability to respond, the total GCS score was still seen to have a better predictive utility than just relying on its motor part for in-hospital mortality, receipt of neurosurgical interventions, meeting criteria for severe brain injury, and emergency intubation. ${ }^{6}$

Haghparast-Bidgoli et al. (2013) found that a lower GCS score was associated with a longer length of stay in the hospital. ${ }^{3}$ In this study, those who had more severe injuries were almost thrice more likely to stay longer in the hospital compared to those with less severe injury. Specifically, those who suffered head and neck injuries generally had longer length of hospital stay. However, this association should be interpreted with caution. Those who die are also more likely to have low coma scores, and death is associated with a shorter length of stay in the hospital, as in the results of Haghparast-Bidgoli et al. ${ }^{3}$ On the other hand, the association may still hold true since the association was even attenuated when mortality status was controlled for in the model. Another possible explanation is that severe injuries will need longer management and period in order to recover optimum health. ${ }^{8,9}$

Among the three types of victims, drivers had the highest risk of staying longer in the hospital, followed by pedestrians, and lastly passengers. In the cohort analysis conducted in Cameroon, vulnerable road users or those who were users of motorized two-wheelers and pedestrians represented over $80 \%$ of the overall road injury victims. Passengers and non-motorized road users were also more likely be admitted and have longer recovery periods in the hospital as compared to drivers. ${ }^{10}$ However, in our study, the association between being a pedestrian and the length of hospital stay was not significant. In the study by Qiu et al. (2016), pedestrians sustained the greatest number of deaths compared to drivers and passengers while the passengers sustained the greatest number of non-fatal injuries as compared to drivers and pedestrians. ${ }^{11}$ In addition, a study in three cities in Metro Manila, Philippines showed that there were multiple factors and combinations of factors that increased the potential for serious injury among pedestrians in this lower-middle-income country. These include traffic patterns involving heavy vehicles and varying subgroups of pedestrians, patterns of traffic violations involving the range of street users, and absence of accessible and safe pedestrian infrastructure. ${ }^{12}$ Thus, the overall risk of staying long in the hospital should not be ignored for pedestrians.

Those who died stayed shorter in the hospital, since their condition was already severe, and they didn't last long despite interventions done in the hospital. A previous study found that death related to road traffic crash in Ethiopia was due to seriousness of injuries and lack of hospital emergency care services. ${ }^{13}$ This is supported by a study done in Guinea on which about $0.7 \%$ of road traffic crash victims brought to the hospital were dead on arrival while $0.6 \%$ died in the emergency department, all deaths occurred within 24 hours. ${ }^{14}$ At the global level, more than 1.25 million people die annually as a result of road traffic crashes. ${ }^{15}$

There were non-significant associations for age, sex and the length of stay in this study. This is contrary to the results of the study based on the Iranian National Trauma Registry Database (INTRD) which covered 14 general hospitals in 8 major cities in Iran. The study showed that being male was associated with a longer length of hospital stay, together with other variables including lower educational level, having a medical insurance, being a blue-collar, worker being a pedestrian or motorcyclist, having higher ISS score or having lower GCS score. ${ }^{3}$ Similarly, a study done in Iran found that older men were 1.15 times more prone to stay in the hospital compared to women. ${ }^{16}$ In this study, while women were seen to have a slightly higher risk of staying longer in the hospital as compared to males, this was not significant.

A review of published trauma registry literature from lowand middle-income countries conducted by Boughton et al (2015) showed that young, male, road traffic victims represent a large proportion of the trauma burden. ${ }^{17}$ Furthermore, on a study done in Kenyatta National Hospital young men in the reproductive years with low educational level who were unemployed were found to be the most affected by road traffic crashes leading to admission at critical care unit. ${ }^{18}$

If the model was run solely on the basis of including variables only if they have statistically significant results in the likelihood ratio test, only mortality status and type of victim would be retained in the model. Mortality status has been found to be a consistent determinant of length of stay in the hospital, and the findings of the study are similar to the findings of Gardner et al. (2007), Haghparast-Bidgoli et al. (2013) and Araujo \& Whitaker (2016) which also claimed that mortality is associated with a shorter length of stay in the hospital. ${ }^{2,3,19}$ Contrary to that, Chelogoi et.al (2018) found that length of stay was not significantly associated with mortality $(\mathrm{p}>0.05) .{ }^{18}$

The type of victim is also considered to be an important determinant of road traffic injury, with previous studies showing that pedestrians have a longer length of stay than those inside vehicles. ${ }^{3}$ Contrary to that, a study done in Brazil found that longest hospital stay was for the truck occupant followed by the pedestrian and car occupant. ${ }^{20}$ Compared to the previous study, we concluded that the risk of staying longer was highest for drivers, followed by pedestrians, and lastly, passengers. However, this difference between the findings of the study and the published literature may lie in part in the way the variables are coded in the published literature. It is noteworthy that the study did not make a distinction between passengers and drivers. 
The results of the study can be used for managing the resources of the PGH. Hospital staff can predict that patients with more severe injury, granted that they did not die, and those who were drivers and pedestrians, are more likely to stay longer in the PGH.

These findings also imply that there should probably be more safety interventions for drivers (of cars, bicycles, and motorcycles) to minimize the severity of their injury, and to shorten their stay in the hospital. The World Health Organization (2018) stated that wearing motorcycle helmets can reduce the risk of death by almost $40 \%$, as well as the risk of severe injuries..$^{15}$ Results of a study based on the Head Injury Registry in Taiwan showed that using full-coverage and partial-coverage motorcycle helmets can significantly decrease the risk of cervical spine injury among head injury patients from motorcycle crashes. The design of the helmet includes the smooth surface and hard linings of padding materials, as shown by previous biomechanical analyses. ${ }^{21}$ Erhardt et al. (2016) also found that the helmet type had a strong effect on head injury risk, and that full-face and modular helmets were the most protective types followed by open-face helmets, half-helmets, and novelty helmets. ${ }^{22}$ From the findings, only $43 \%$ of motorcycle and bicycle riders were using helmets at the time of their accident.

According to the World Health Organization (2018), the risk of having a road traffic crash starts at low levels of blood alcohol concentration (BAC) and significantly increases when it reached $\geq 0.04 \mathrm{~g} / \mathrm{dl} .{ }^{15}$ Mortality rate due to a traffic crash in patients with alcohol use doubled compared to sober patients, as seen by Stubig et al. (2012) in their study on trauma to road users from 1999 to 2010 in Germany. ${ }^{23}$ In addition, Harada et al. (2015) found out in a study that intoxicated cyclists were less likely to wear helmets. ${ }^{24}$ Among all drivers included in this study, around $74 \%$ were intoxicated at the time of the accident. Similarly, a study that used toxicological investigation reports from Department of Forensic Medicine and Toxicology of the University of Athens found that many (40.7\%) road traffic crash-related fatalities were associated with alcohol consumption, of which about 20.3\% were car drivers. A higher frequency of road traffic crash fatalities was associated with BAC of $>110 \mathrm{mg} /$ $\mathrm{dL}$, which was encountered in younger age groups. ${ }^{25}$

The findings of the study are a good start in studying the determinants of prolonged hospital stay in the PGH. There is no lost-to-follow-up in this study, however, there is substantial missing data problem on some variables. Only 176 (41.2\%) of all patients were included in the regression analysis. As such, doctors and nurses responsible for taking patient information and preparing the charts should be trained to collect patient information consistently. This will minimize missing data and provide better quality evidence.

Finally, drivers and pedestrians were shown to have higher risk of staying longer, which is, in large part, due to poor compliance to rules and regulations. There should be stricter implementation of drunk driving and helmet laws. ${ }^{26}$
Furthermore, other safety features for drivers should also be explored. Heydari et. Al. (2019) mentioned that for most low-income countries where there are multi-sector problems, a combination of insights and experience from experts will provide a better approach to improve road safety. ${ }^{27}$

\section{CONCLUSION}

The type of victim, mortality status, age and sex are important determinants of prolonged hospitalization. In addition, those who receive first aid and avail services, and who had a married civil status had significant associations to length of hospital stay. To lessen number of fatalities and road trauma injuries, there should be stricter implementation of laws pertaining to road safety. Moreover, each stakeholder should ensure safe usage of road as it is shared among all types of road users.

\section{Acknowledgment}

This study is part of the funding from the Emerging Interdisciplinary Research (EIDR) Program of the University of the Philippines.

\section{Statement of Authorship}

All authors participated in the data collection and analysis and approved the final version submitted.

\section{Author Disclosure}

All authors declared no conflicts of interest.

\section{Funding Source}

This study was funded by the Emerging Interdisciplinary Research (EIDR) Program of the University of the Philippines.

\section{REFERENCES}

1. Western Pacific Region Office [Internet]. Geneva: World Health Organization; c2017 [cited 2017 September 28]. Injury and violence; [about 3 screens]. Available from: http://www.wpro.who.int/ philippines/areas/injury_violence/continuation_injury_and_violence_ area_page/en/.

2. Gardner R, Smith GA, Chany AML, Fernandez SA, McKenzie LB. Factors associated with hospital length of stay and hospital charges of motor vehicle crash related hospitalizations Among Children in the United States. Arch Pediatr Adoles Med. 2007 Sep; 161(9):889-95.

3. Haghparast-Bidgoli H, Saadat S, Bogg L, Yarmohammadian MH, Hasselberg M. Factors affecting hospital length of stay and hospital charges associated with road traffic-related injuries in Iran. BMC Health Serv Res. 2013 Jul; 13:281.

4. Lam HY, Rivera AS, Macalino JU, Quebral JD, Cheng KJ, Miguel RTD. Estimating the social and economic burden of road traffic injuries in the Philippines. Acta Med Philipp. 2018 Sep; 52(5):423-8.

5. Chazard E, Ficheur G, Beuscart JB, Preda C. How to compare the length of stay of two samples of inpatients? a simulation study to compare type I and type II errors of 12 statistical tests. Value Health. 2017 Jul-Aug; 20(7):992-8.

6. Chou R, Totten AM, Carney N, Dandy S, Fu R, Grusing S, et al. Predictive utility of the Total Glasgow Coma Scale versus the Motor 
Component of the Glasgow Coma Scale for identification of patients with serious traumatic injuries. Ann Emerg Med. 2017; 70(2):143-57.

7. Alqarni AA, Alanazi RG, Morgan A, Alharbi AS, Aljuaid FF, Aldawsari AM, et al. Injuries type and its telation with Glasgow Coma Scale, Injury Severity Score and blood transfusion in road traffic accident victims. Med Perspekt. 2018; 23(2):148-59.

8. Tesfay K, Assefa M, Zenebe D, Gebremicael M, Kebede G, Gebrekirstos H. Road traffic injured patients with severe GCS and organ injury had a poor prognosis: a retrospective cohort study. BMC Public Health. 2019 Jun 13; 19(1):749.

9. Santolino M, Bolancé C, Alcañiz M. Factors affecting hospital admission and recovery stay duration of in-patient motor victims in Spain. Accid Anal Prev. 2012 Nov; 49:512-9.

10. Chichom-Mefire A, Palle-Ngunde J, Fokam PG, Mokom-Awa A, Njock R, Ngowe-Ngowe M. Injury patterns in road traffic victims comparing road user categories: analysis of 811 consecutive cases in the emergency department of a level I institution in a low-income country. Int J Surgery Open. 2018; 10:30-6.

11. Qiu J, Li Y, Jiang Z, Yuan D, Li Y, Zhang L, et al. Analysis of road traffic injuries by road user type in Chongqing, China. Hong Kong J Emerg Med. 2016 Jan; 23(1):34-41.

12. Verzosa, N, Miles R. Severity of road crashes involving pedestrians in Metro Manila, Philippines. Accid Anal Prev. 2016 Sep; 94:216-26.

13. Woyessa AH, Heyi WD, Ture NH, Moti BK. Patterns of road traffic accident, nature of related injuries, and post-crash outcome determinants in western Ethiopia-a hospital based study. Afr J Emerg Med. 2021 Mar; 11(10):123-31.

14. Kourouma K, Delamou A, Lamah L, Camara BS, Kolie D, Sidibé S, et al. Frequency, characteristics and hospital outcomes of road traffic accidents and their victims in Guinea: a three-year retrospective study from 2015 to 2017. BMC Public Health. 2019 Jul 31; 19(1):1-12.

15. World Health Organization [Internet]. Geneva: World Health Organization; c2021 [cited 2018 October 18]. Road traffic injuries; [about 3 screens]. Available from: http://www.who.int/news-room/ fact-sheets/detail/road-traffic-injuries.

16. Yadollahi M, Pazhuheian F, Jamali K, Hadi Niakan M. (2020). Hospitalization due to traffic accidents among the elderly, Shiraz, 2018; mortality, severity, and injury pattern. Arch Trauma Res. 2020 Jul-Sep; 9(3):106-10.

\section{APPENDICES}

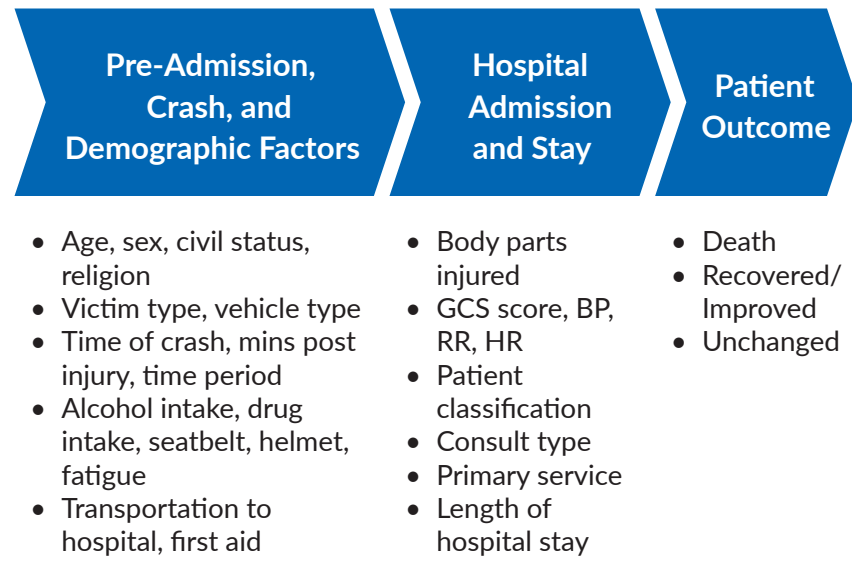

Appendix 1. Conceptual Framework of the Determinants of Length of Hospitalization.

Adopted and modified from Wright SP, Verouhis D, Gamble G, Swedberg K, Sharpe N, Doughty RN. (2003).
17. Boughton O, Jones GG, Lavy CBD, Grimes CE. Young, male, road traffic victims: a systematic review of the published trauma registry literature from low and middle income countries. SICOT-J. 2015 Jun $15 ; 1: 10$.

18. Chelogoi IE, Karanja S, Kombe Y. Characteristics and health outcomes of patients with road traffic injuries managed in critical care unit at Kenyatta National Hospital: a one year retrospective cohort study. Afr J Health Sci. 2018 Jan-Mar; 31(1):108-20.

19. Araujo GL de, Whitaker IY. Hospital morbidity of injured motorcyclists: factors associated with length of stay. Acta Paul Enferm. 2016; 29(2):178-84.

20. Andrade SSC, Jorge MHP. Hospitalization due to road traffic injuries in Brazil, 2013: hospital stay and costs. Epidemiol Serv Saude. 2017 Jan-Mar; 26(1):31-8.

21. Lam C, Lin MR, Chu SF, Tsai SH, Bai CH, Chiu WT. The effect of various types of motorcycle helmets on cervical spine injury in head injury patients: a multicenter study in Taiwan. Biomed Res Int. 2015 Feb; 2015:487985. PMID: 25705663.

22. Erhardt T, Rice T, Troszak L, Zhu M. Motorcycle helmet type and the risk of head injury and neck injury during motorcycle collisions in California. Accid Anal Prev. 2016 Jan; 86:23-8.

23. Stübig T, Petri M, Zeckey C, Brand S, Müller C, Otte D, et al. Alcohol intoxication in road traffic accidents leads to higher impact speed difference, higher ISS and MAIS, and higher preclinical mortality. Alcohol. 2012 Nov; 46(7):681-6.

24. Harada MY, Gangi A, Ko A, Liou DZ, Barmparas G, Li T, et al. Bicycle trauma and alcohol intoxication. Int J Surg. 2015; 24(Pt A):14-9.

25. Papalimperi AH, Athanaselis SA, Mina AD, Papoutsis II, Spiliopoulou CA, Papadodima SA. Incidence of fatalities of road traffic accidents associated with alcohol consumption and the use of psychoactive drugs: a 7-year survey (2011-2017). Exp Ther Med. 2019 Sep; 18(3): 2299-306.

26. O'Connor LR, Ruiz RAL. Alcohol and hospitalized road traffic injuries in the Philippines. Yale J Biol Med. 2014 Sep 3; 87(3):307-19.

27. Heydari S, Hickford A, McIlroy R, Turner J, Bachani, AM. Road safety in low-income countries: state of knowledge and future directions. Sustainability. 2019 Nov; 11(22):6249.

Appendix 2. Distribution of patients according to month of injury

\begin{tabular}{|c|c|}
\hline Month & Valid Frequency (\%) \\
\hline January & $36(8.8)$ \\
\hline February & $34(8.3)$ \\
\hline March & $31(7.6)$ \\
\hline April & $32(7.8)$ \\
\hline May & 57 (13.9) \\
\hline June & $44(10.7)$ \\
\hline July & $29(7.1)$ \\
\hline August & $22(5.4)$ \\
\hline September & $20(4.9)$ \\
\hline October & $101(24.6)$ \\
\hline November & $2(0.5)$ \\
\hline December & $2(0.5)$ \\
\hline Missing & 17 \\
\hline Total & 427 \\
\hline
\end{tabular}




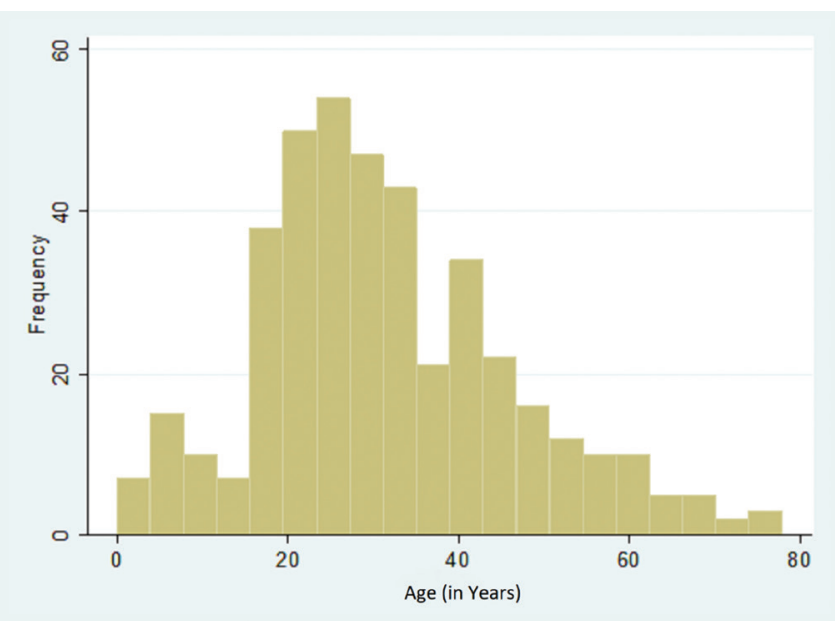

Appendix 3. Distribution of patients according to age.

Appendix 5. Distribution of patients according to GCS score by the time of admission ( $N=427)$

\begin{tabular}{|c|c|}
\hline GCS score & Valid Frequency (\%) \\
\hline 3 & $5(2.5)$ \\
\hline 4 & $3(1.5)$ \\
\hline 5 & $3(1.5)$ \\
\hline 6 & $4(2.0)$ \\
\hline 7 & $1(0.5)$ \\
\hline 8 & $4(2.0)$ \\
\hline 9 & $5(2.5)$ \\
\hline 10 & $7(3.5)$ \\
\hline 11 & $3(1.5)$ \\
\hline 12 & $7(3.5)$ \\
\hline 13 & $15(7.4)$ \\
\hline 14 & $19(9.4)$ \\
\hline 15 & $127(62.6)$ \\
\hline Missing & 224 \\
\hline Total & 427 \\
\hline
\end{tabular}

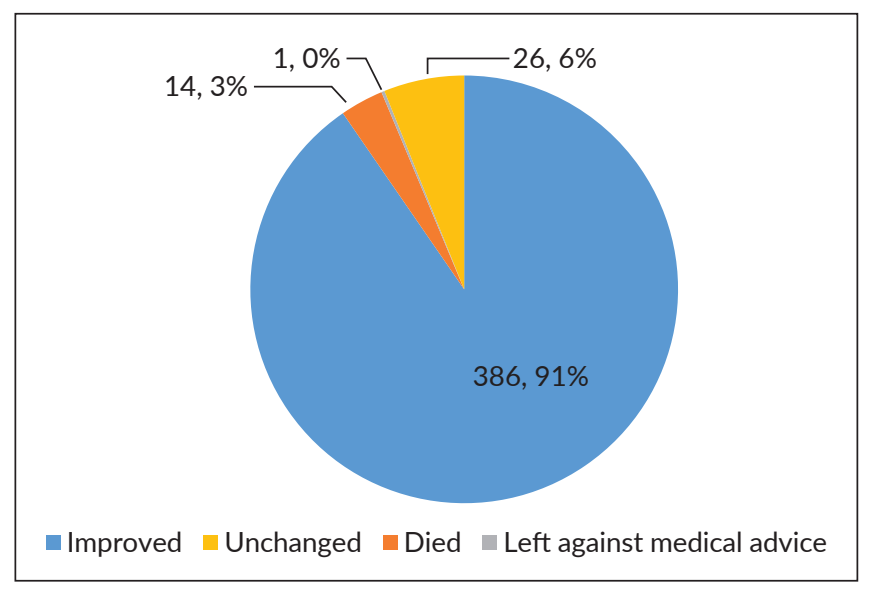

Appendix 7. Distribution of patients according to outcome of treatment.

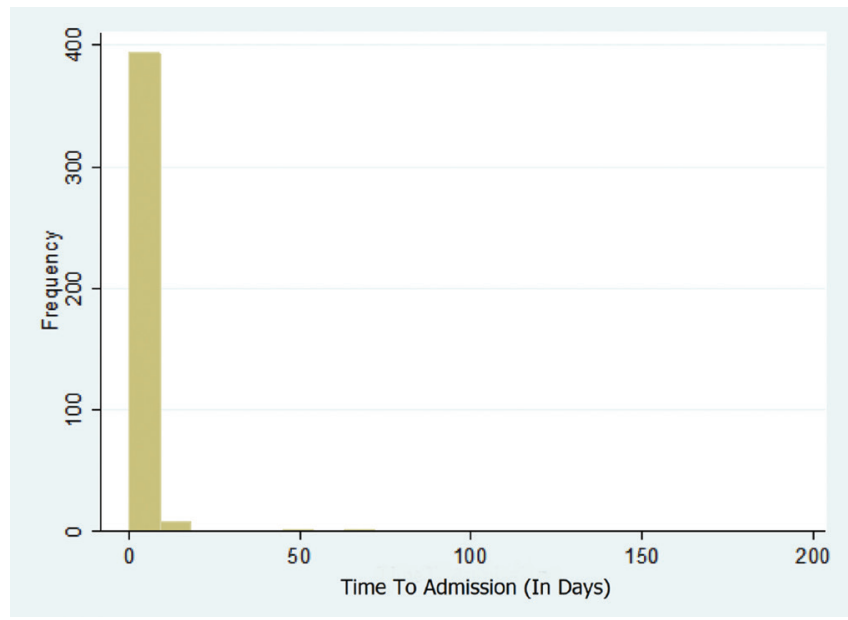

Appendix 4. Distribution of patients according to time to admission $(n=413)$.

Appendix 6. Distribution of patients according to the type of service $(\mathrm{N}=427)$

\begin{tabular}{lc}
\hline \multicolumn{1}{c}{ Service } & Frequency (\%) \\
\hline Trauma & $325(76.1)$ \\
Plastic Surgery & $38(8.9)$ \\
Surgeon-on-duty & $27(6.3)$ \\
Neurosurgery & $11(2.6)$ \\
Hepatobiliary Surgery & $1(0.2)$ \\
Gastrointestinal Surgery & $2(0.5)$ \\
Head and Neck Surgery & $1(0.2)$ \\
Orthopedics & $5(1.2)$ \\
Pediatric Surgery & $5(1.2)$ \\
Ear, Nose and Throat & $1(0.2)$ \\
Internal Medicine & $3(0.7)$ \\
Pediatrics & $6(1.4)$ \\
Burn & $1(0.2)$ \\
Obstetrics and Gynecology & $1(0.2)$ \\
\hline
\end{tabular}

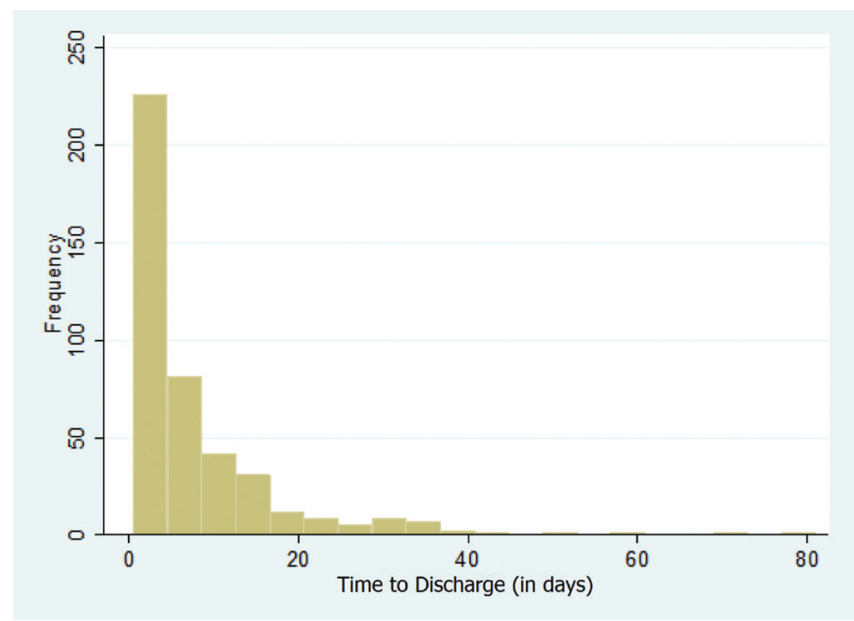

Appendix 8. Distribution of patients according to time to discharge $(\mathrm{N}=427)$. 


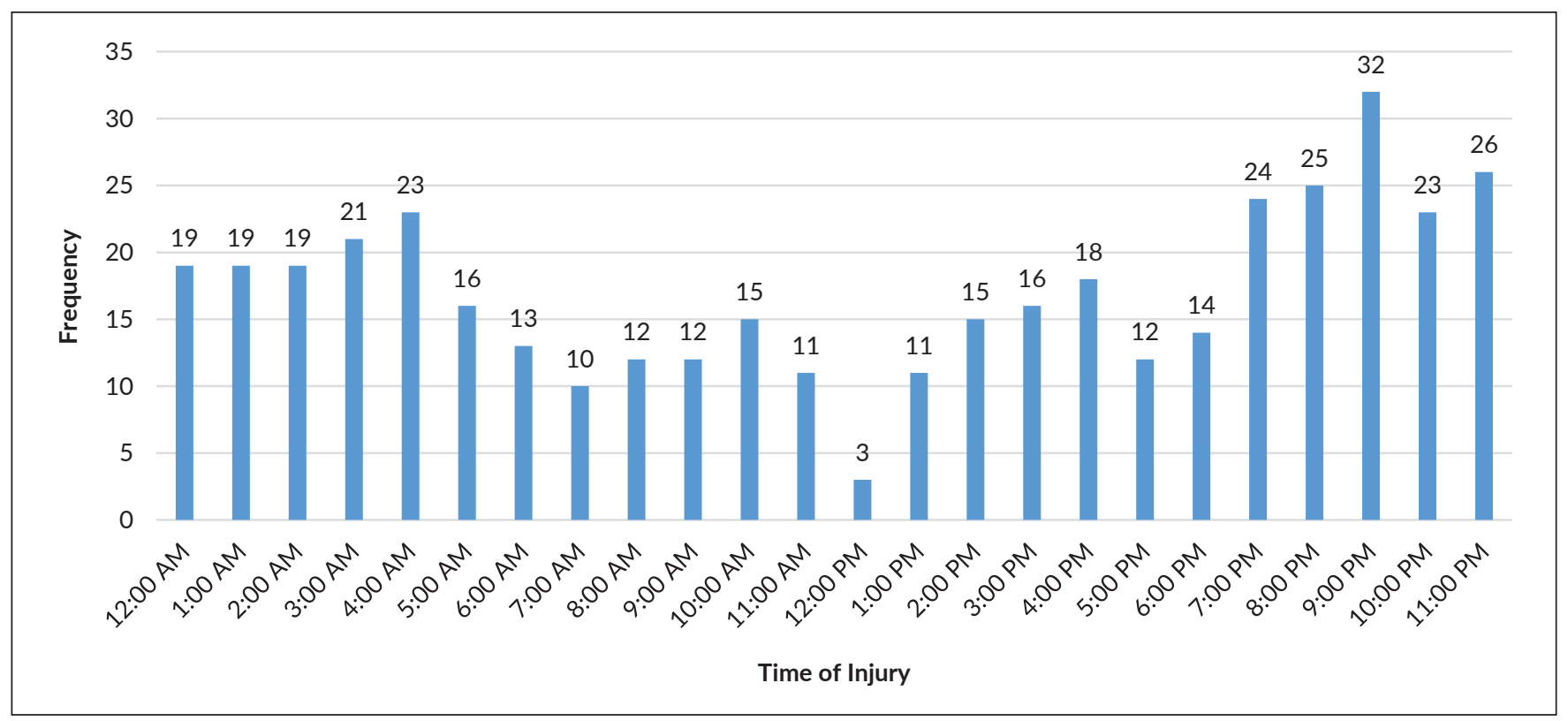

Appendix 9. Distribution of patients according to time to discharge.

Appendix 10. Crude odds ratios of the association of various exposure with length of stay in hospital

\begin{tabular}{lccc}
\multicolumn{1}{c}{ Variable } & $\begin{array}{c}\text { Crude } \\
\text { Odds Ratio }\end{array}$ & $95 \%$ Cl & p-value \\
\hline Time of injury & 1.16 & $0.76-1.78$ & 0.48 \\
Time to admission* & 1.03 & $1.00-1.06$ & 0.06 \\
$\begin{array}{l}\text { Pay Scheme - Pay Patients } \\
\quad \text { Charity }\end{array}$ & 3.46 & $1.36-9.87$ & $<0.01$ \\
$\begin{array}{l}\text { Type of Admission - Elective } \\
\quad \text { Emergency }\end{array}$ & 7.88 & $2.64-31.61$ & $<0.01$ \\
Service availed/Ward - Other & 2.07 & $1.29-3.36$ & $<0.01$ \\
$\quad$ wards other than Trauma & & & \\
Age* & 1.00 & $0.99-1.02$ & 0.64 \\
Sex & 0.81 & $0.47-1.37$ & 0.40 \\
Religion & 1.04 & $0.47-2.32$ & 0.91 \\
Civil Status - Married & 1.52 & $1.00-2.32$ & 0.04 \\
Co-morbidities & 1.08 & $0.56-2.11$ & 0.80 \\
Mortality & 0.62 & $0.16-2.09$ & 0.39 \\
\hline Risky Driving Behaviors & & & \\
$\quad$ Intoxicated & 0.75 & $0.36-1.55$ & 0.40 \\
$\quad$ Not Wearing of Helmet & 1.36 & $0.62-2.99$ & 0.40 \\
\hline Did Not Receive First Aid & 0.55 & $0.35-0.85$ & $<0.01$ \\
\hline Body Part Injured & & & \\
$\quad$ Head & 1.20 & $0.72-1.99$ & 0.46 \\
$\quad$ Torso & 1.04 & $0.70-1.56$ & 0.82 \\
$\quad$ Limbs & 1.32 & $0.81-2.14$ & 0.24 \\
\hline GCS & 1.53 & $0.73-3.24$ & 0.22 \\
\hline
\end{tabular}

\begin{tabular}{|c|c|c|c|}
\hline Variable & $\begin{array}{l}\text { Crude } \\
\text { Odds Ratio }\end{array}$ & $95 \% \mathrm{Cl}$ & p-value \\
\hline \multicolumn{4}{|l|}{ Vehicle of Patient } \\
\hline Patient was in a bike & 0.63 & $0.22-1.64$ & 0.30 \\
\hline Patient was in a car & 0.92 & $0.33-2.49$ & 0.85 \\
\hline Patient was in a tricycle & 1.03 & $0.40-2.62$ & 0.94 \\
\hline Patient was in a motorcycle & 1.20 & $0.78-1.83$ & 0.39 \\
\hline \multicolumn{4}{|l|}{ Type of Victim } \\
\hline Patient was a pedestrian & 0.91 & $0.54-1.52$ & 0.69 \\
\hline Patient was a driver & 1.37 & $0.88-2.13$ & 0.14 \\
\hline Patient was a passenger & 0.59 & $0.29-1.14$ & 0.09 \\
\hline \multicolumn{4}{|l|}{ Other Party in the Accident } \\
\hline $\begin{array}{l}\text { Other party in the accident is } \\
\text { the road }\end{array}$ & 0.91 & $0.55-1.49$ & 0.69 \\
\hline $\begin{array}{l}\text { Other party in the accident } \\
\text { are other obstacles }\end{array}$ & 1.69 & $0.76-3.83$ & 0.16 \\
\hline $\begin{array}{l}\text { Other party in the accident is } \\
\text { a bicycle }\end{array}$ & 0.83 & $0.36-1.88$ & 0.64 \\
\hline $\begin{array}{l}\text { Other party in the accident is } \\
\text { a motorcycle }\end{array}$ & 0.75 & $0.42-1.33$ & 0.29 \\
\hline $\begin{array}{l}\text { Other party in the accident is } \\
\text { a jeepney/bus }\end{array}$ & 1.19 & $0.55-2.48$ & 0.62 \\
\hline $\begin{array}{l}\text { Other party in the accident is } \\
\text { a truck/train/forklift }\end{array}$ & 2.03 & $0.97-4.37$ & 0.04 \\
\hline $\begin{array}{l}\text { Other party in the accident is } \\
\text { a pedestrian/animal }\end{array}$ & 1.48 & $0.25-10.26$ & 0.61 \\
\hline
\end{tabular}

*Logistic Regression

$\mathrm{Cl}$, Confidence Interval 